Research Article

\title{
Model Updating and Global Eigenvalue Analysis of a Tie-Bolt Rotor Using Zero-Length Contact Elements under Different Preloads
}

\author{
Pu Li iD and Qi Yuan (iD \\ School of Energy and Power Engineering, Xi'an Jiaotong University, Xi'an 710049, China \\ Correspondence should be addressed to Pu Li; lipu1215@xjtu.edu.cn
}

Received 29 December 2020; Revised 27 February 2021; Accepted 6 May 2021; Published 19 May 2021

Academic Editor: Wahyu Caesarendra

Copyright ( $2021 \mathrm{Pu} \mathrm{Li}$ and Qi Yuan. This is an open access article distributed under the Creative Commons Attribution License, which permits unrestricted use, distribution, and reproduction in any medium, provided the original work is properly cited.

\begin{abstract}
Tie-bolt rotors are composed of several disks fastened by tie bolts where contact properties have a great influence on the modal behavior. In this work, a linear spring-damper element is used to consider the contact stiffness and damping in a tie-bolt rotor. A tie-bolt rotor model is developed using the beam element and the zero-length contact element. Experimental modal testing is performed under different preloads of tie bolts. Model updating is carried out to tune the contact parameters using the Particle Swarm Optimization algorithm. Furthermore, a global eigenvalue evaluation is carried out to demonstrate the impact of the lumped spring-damper element on the modal results. Results show that a larger pretension reduces the influence of contact damping on modal parameters. Compared to antisymmetric modes, symmetric modes are more sensitive to the change of contact damping.
\end{abstract}

\section{Introduction}

Tie-bolt rotors are commonly encountered in a wide range of turbomachinery such as in gas turbines and aero-engines [1-3]. Laminated rotors represent another kind of tie-bolt rotors used in induction motors [4-6]. Compared to traditional forged rotors, tie-bolt rotors are composed of several disks fastened by one or more tie-bolts that render a convenient approach to be manufactured and assembled. However, the presence of tie bolts affects the dynamics of combined rotors. For instance, macroslip of adjacent disks due to loosening of the tie bolt threatens the integrity of the combined structure [7-9]. Bolt loosening can be regarded as an excitation that may cause an increasing response [7]. The stiffness of the combined structure is reduced, which induces nonlinear dynamics [8]. A similar jointed configuration has been used in space structures [10]. Nonlinear dynamics of tie-bolt rotors are discussed in [11-13].

Understanding the modal response to a varying preload in a tie-bolt rotor is helpful in analyzing the dynamics of such structures. To consider the effect of joint connection, it is necessary to model the stiffness and damping appropriately. The natural frequency of tie-bolt rotors increases with an increasing preload. To better describe the physical phenomenon, the zero-length element and the thin-layer element are widely used to depict the behavior of the joints [14]. A detailed literature review is provided in [15]. Using the zero-length element, we can distinguish between the lumped element $[2,16]$ and the contact element $[17,18]$, which are widely adopted to examine the influence of the contact stiffness on the natural frequency. The thin-layer element is originally applied in soil-structure interaction analysis [19]. Material properties of the thin layer are modified to consider the stiffness of the contact interface under different preloads [20]. By adopting the thin-layer elements, we obtain an accurate finite element model using model updating [21, 22]. The damping properties have been investigated by updating the proportional coefficients of the thin-layer element $[14,23]$.

The Greenwood-Williamson (GW) statistical model is commonly applied to describe the pressure distribution between contact pairs [24-26]. Compared to the GW model 
that is based on the Hertzian normal contact model for two elastic spheres, the Jackson-Green (JG) model considers the plastic deformation [27]. Energy dissipation of the assembled structure is closely related to interface damping. Considering the hysteresis loop of joints, the Vanalis model has been adopted to describe the mechanics of microslip and macroslip [28]. The Iwan model represents a widely used constitutive element for the elastic-plastic behavior of joints $[14,29]$. However, the controlling variables of the contact model, such as the four parameters of the Iwan model, are usually unknown. As a result, model updating based on experimental results is required to determine the parameters of contact models.

Experimental modal testing is commonly performed to investigate the influence of contact pretension [30], surface roughness [18], and interference fits [31] on the natural frequency. Furthermore, the effect of bending moment on the dynamic behavior has been investigated in $[1,32,33]$. Bolt loosening is a practical issue that can be accomplished by modal testing [25] as well as a noncontact laser approach [34]. Bolt loosening induces a perturbation of external force, and the corresponding response of a tie-bolt rotor has been analyzed and validated [7].

Most of the previous studies focus on the contact stiffness of the combined structure, and damping properties are rarely studied for the tie-bolt rotor. The influence of contact stiffness and damping on the modal response has not been well understood. This work aims to investigate a global eigenvalue behavior of a tie-bolt rotor under different preloads. The relationship between contact parameters and modal response is clarified. The rest of the paper is organized as follows. In Section 2, a tie-bolt rotor model is introduced by using the beam element and lumped spring-damper element. Based on the governing equations of the rotor, an eigenvalue evaluation is illustrated. In Section 3, experimental modal testing is demonstrated. Model updating is carried out based on the experimental results. Analytical sensitivity is derived to validate the modal testing. In Section 4, a global eigenvalue evaluation is performed to illustrate the general influence of contact parameters on the modal parameters, followed by a discussion of modeling techniques of the interface in Section 5. The paper is concluded in Section 6. The finite element matrices are collected in Appendix.

\section{Rotor Modeling}

From a modeling perspective, the finite element method (FEM) is the most used tool for rotor dynamics. 3D solid finite elements render direct virtual prototyping from CAD data, and at the same time, they can handle unsymmetrical characteristics, such as blades, with high accuracy. However, the computational cost is very high, especially for large shafttrain systems. To circumvent the problem, model reduction is usually performed for stability analysis [35] or transient simulations [36]. As a result, in most industrial applications, the beam element is applied in the standard approach of rotor dynamics. Nelson's pioneering work lays a foundation for the development of the beam element for rotor modeling
[37]. The beam model, or called the shaft-line model [38], is a linearized approach where the rotor system is represented by a series of finite beam elements. The most significant modification is the stiffness of the components due to the assumption of the element. Therefore, the stiffness diameter should be modified according to industrial experiences or by adopting the strain energy method.

In this paper, the rotor is fastened by four groups of tie bolts to connect shaft ends and fasten disks, as displayed in Figure 1. In the following discussion, the tie bolts connecting shaft ends are not taken into account. A large preload torque is applied and kept constant. To demonstrate the influence of preloads on the modal parameters, we change the tightening torque of the bolts that connects two disks, and the status of four contact pairs is altered accordingly.

First of all, we need to determine the stiffness diameter that is different from the diameter of the rotor. We apply the strain energy method and calculate the stiffness diameter $D_{e}^{i}$ of the rotor segment $i$ according to

$$
D_{e}^{i}=\left(\frac{32 M^{2} l^{e}}{\pi E U_{b}}\right)^{0.25},
$$

where $E$ denotes elasticity modulus, $M$ and $U_{b}$ are applied bending moment and the corresponding strain energy, respectively, and $l^{e}$ represents the length of the $i$ th rotor part. The rotor is discretized into 51 elements along the axis involving four zero-length contact elements. Therefore, the rotor has 52 nodes, as plotted in Figure 2. The mass radius and the stiffness radius depict the actual geometry of the rotor and the bending stiffness reduction due to the abrupt change of diameter.

2.1. Beam Rotor Element. A beam element with four degrees per node is used to develop the rotor model, as displayed in Figure 3. Therefore, the lateral displacement and the angle at node $n$ and $n+1$ can be expressed as

$$
\begin{aligned}
r_{n}^{e}(t) & =\left[\begin{array}{llll}
y_{n}^{e} & \phi_{y, n}^{e} & z_{n}^{e} & \phi_{z, n}^{e}
\end{array}\right], \\
r_{n+1}^{e}(t) & =\left[\begin{array}{llll}
y_{n+1}^{e} & \phi_{y, n+1}^{e} & z_{n+1}^{e} & \phi_{z, n+1}^{e}
\end{array}\right],
\end{aligned}
$$

where $e$ stands for the element. by

The corresponding displacement of the element is given

$$
r^{e}=\left[\begin{array}{ll}
r_{n}^{e} & r_{n+1}^{e}
\end{array}\right]^{T} \in \mathbb{R}^{8 \times 1}
$$

2.2. Contact Element. As displayed in Figures 2 and 4, we introduce the contact element at nodes 20(21), 24(25), and 28(29) and 32(33). The stiffness and damping matrices of the contact element are shown in Appendix. As can be seen, the stiffness properties are defined by axial stiffness $k_{a}$ as well as rotational stiffness $k_{c}$, while rotational damping coefficient $d_{c}$ denotes the damping of the element. Supposing the axial and lateral vibration are uncoupled, we do not consider the influence of the axial stiffness $k_{a}$. The influence of preloads can be denoted by the rotational stiffness $k_{c}$ as well as the damping $d_{c}$. 


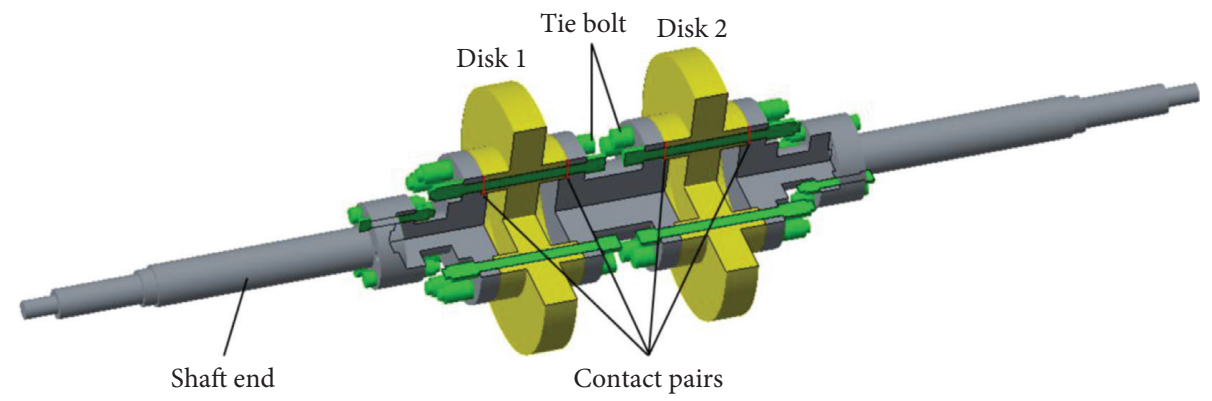

Figure 1: Schematic display of the tie-bolt rotor.

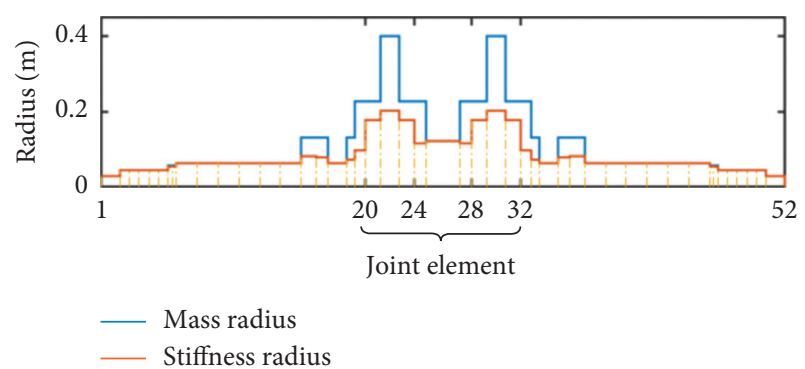

FIgUre 2: Stiffness radius and mass radius of the tie-bolt rotor.

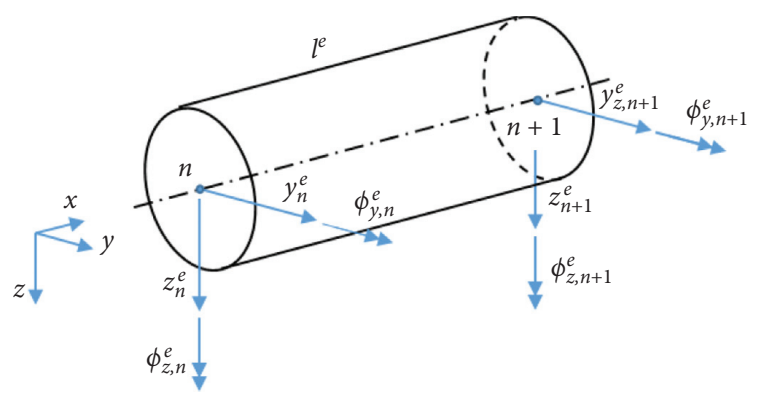

FIGURE 3: Schematic beam element for rotor modeling.

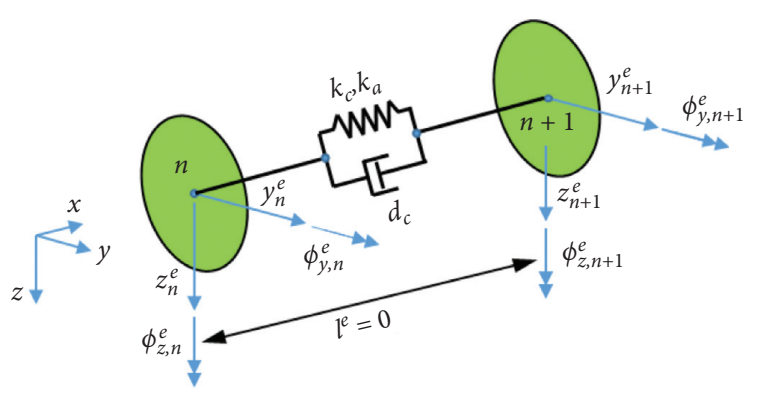

FIGURE 4: Zero-length contact element.

2.3. Eigenvalue Analysis. Assembling the corresponding element matrices (see Appendix) yields the equations of motion of the homogeneous system:

$$
\mathbf{M} \ddot{\mathbf{r}}(t)+\left(\mathbf{B}_{0}+\mathbf{B}_{c}+\mathbf{G}\right) \dot{r}(t)+\left(\mathbf{K}_{0}+\mathbf{K}_{c}\right) \mathbf{r}(t)=\mathbf{0},
$$

where $\mathbf{M}$ represents the mass matrix, $\mathbf{B}_{0}$ and $\mathbf{B}_{c}$ denote the damping matrix for the beam element and the contact element, $\mathbf{K}_{0}$ and $\mathbf{K}_{c}$ are the corresponding stiffness matrix, and $\mathbf{G}$ stands for the gyroscopic matrix. All the matrices of the dimensions $4 N \times 4 N$ are symmetric where $N$ stands for the total number of the nodes.

We focus on the influence of the coupling element on the eigenvalue analysis and, therefore, neglect the damping from the beam element, i.e., $\mathbf{B}_{0}=0$. Thus, the damping term is determined only by the zero-length contact element. The gyroscopic matrix is also zero because the rotational speed is zero. Therefore, the equations of motion can be simplified as

$$
\mathbf{M} \ddot{\mathbf{r}}(t)+\mathbf{B}_{c} \dot{\mathbf{r}}(t)+\left(\mathbf{K}_{0}+\mathbf{K}_{c}\right) \mathbf{r}(t)=\mathbf{0} .
$$

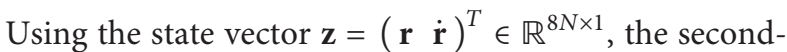
order ODE can be transformed into a state-space representation as

$$
\begin{gathered}
\mathbf{A} \dot{\mathbf{z}}+\mathbf{B z}=\mathbf{0}, \\
\text { with } \mathbf{A}=\left[\begin{array}{cc}
\mathbf{B}_{\mathbf{c}} & \mathbf{M} \\
\mathbf{M} & 0
\end{array}\right] \text { and } \mathbf{B}=\left[\begin{array}{cc}
\mathbf{K}_{0}+\mathbf{K}_{\mathbf{c}} & 0 \\
0 & -\mathbf{M}
\end{array}\right] \text {. }
\end{gathered}
$$

The characteristic polynomial to calculate the eigenvalues $\lambda_{e}$ and eigenvector $\vartheta$ is written as

$$
\left[\lambda_{e} \mathbf{A}+\mathbf{B}\right] \vartheta=\mathbf{0} .
$$

Consequently, we obtain the eigenvalues and corresponding eigenvectors depending on the contact stiffness and damping.

\section{Model Updating of the Rotor System}

3.1. Modal Testing. Impact testing under free-free boundary conditions is performed to investigate the influence of preload on natural frequency and modal damping. Seven PCB accelerometers (Type 333B30) are used to obtain the vibration signals, and the axial locations are shown in Table 1 . The rotor is suspended by elastic cables at two locations, see Figure 5.

The pretension of the tie bolts is controlled by a torque wrench. For the data acquisition system, a resolution of $0.32 \mathrm{~Hz}$ has been used with a frequency range from 0 to $2560 \mathrm{~Hz}$. A roving hammer impact test using the force transducer (Type CL-YD-305A) has been carried out five times per preload case to obtain the modal results. Frequency response functions (FRFs) and coherence diagram of accelerometers 3 and 6 are displayed in Figure 6, where the peaks denote five lateral natural frequencies. To obtain the 
TABLE 1: Axial location of the accelerometer.

\begin{tabular}{lccccccc}
\hline Sensor no. & 1 & 2 & 3 & 4 & 5 & 6 & 7 \\
\hline Axial coordinate $(\mathrm{m})$ & 0.05 & 0.40 & 0.60 & 0.91 & 1.21 & 1.42 \\
Node no. (FE) & 2 & 13 & 17 & 27 & 36 & 41 & 51 \\
\hline
\end{tabular}

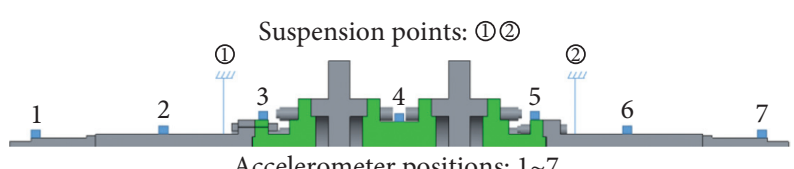

Accelerometer positions: 1 7

FIgURE 5: Modal testing of the tie-bolt rotor under free-free boundary conditions using 7 accelerometers.
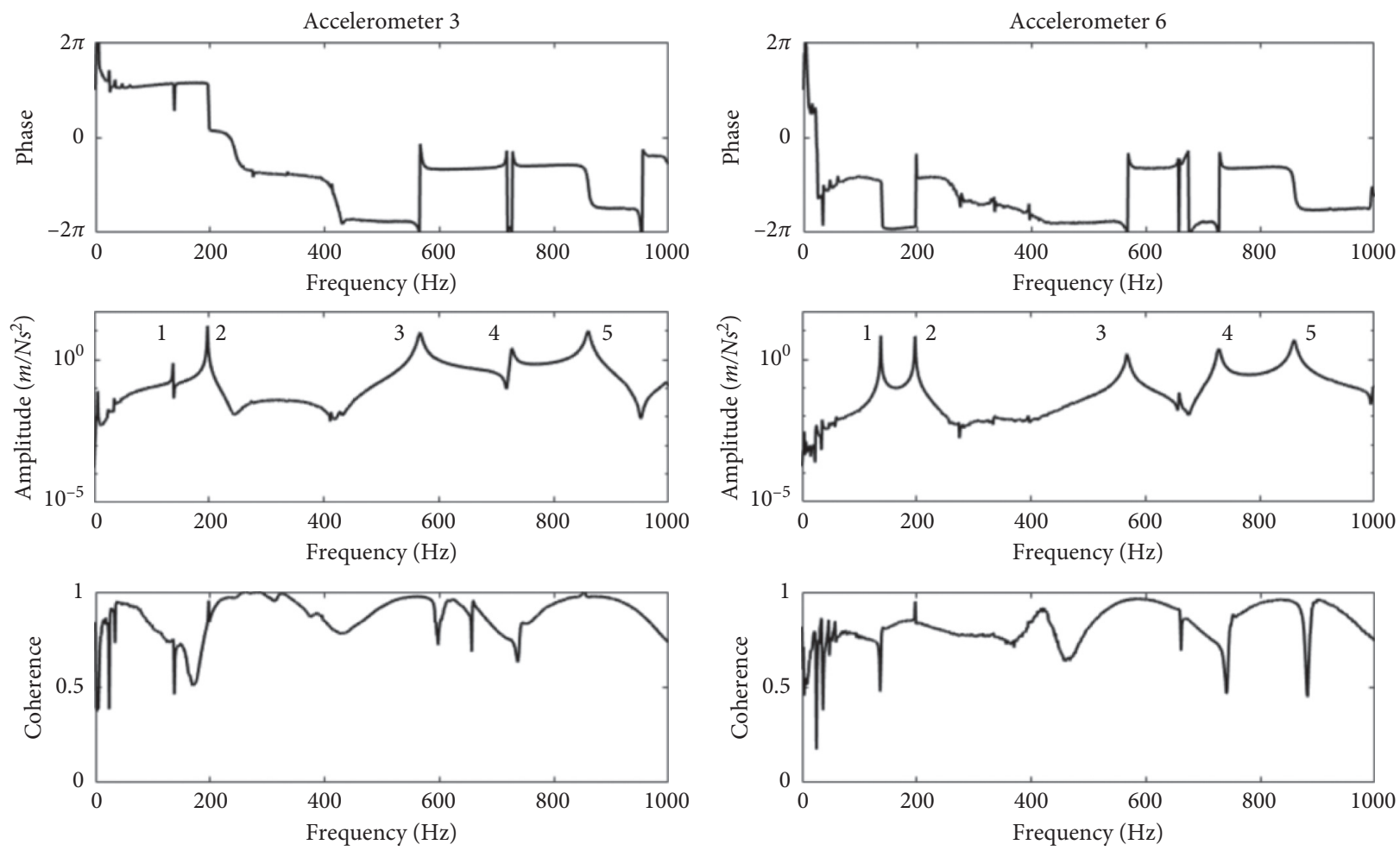

FIGURE 6: Frequency response functions and coherence of the tie-bolt rotor with the preload of $110 \mathrm{Nm}$.

corresponding modal parameter (frequency and modal damping), an experimental modal analysis is carried out. Natural frequency and modal damping ratio are obtained using the PolyMAX frequency-domain method in LMS TestLab.

By performing a series of modal tests with different preloads, modal frequency and damping for the five bending modes are summarized in Figures 7 and 8. We observe a growing frequency and decreasing modal damping versus preload. The $3^{\text {rd }}$ and $5^{\text {th }}$ frequencies experience an increase of $9.0 \%$ and $5.4 \%$ that are more sensitive to the preload than other modes. Concerning modal damping, abnormal behavior at the preload of $70 \mathrm{Nm}$ is due to the interference fit of the contact interface. Further validation is provided by the model updating in Section 3.3.

\subsection{Model Updating Using Particle Swarm Optimization} (PSO). It is inevitable to experience a disparity between simulations and experimental results due to the uncertainty of system parameters. Model updating is a practical tool to tune the input parameters according to experiments. To obtain an accurate rotor model, the contact element parameter and the resulting eigenvalues are adopted to define an input-output optimization problem. Concerning the tie-bolt rotor model, the stiffness modification due to diameter distortion is 


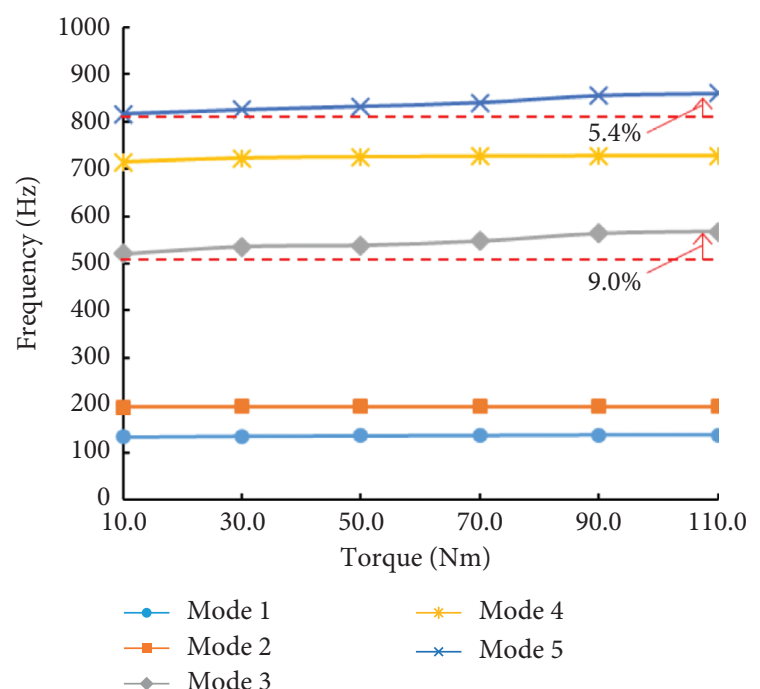

Figure 7: Natural frequency versus preload from 10 to $110 \mathrm{Nm}$.

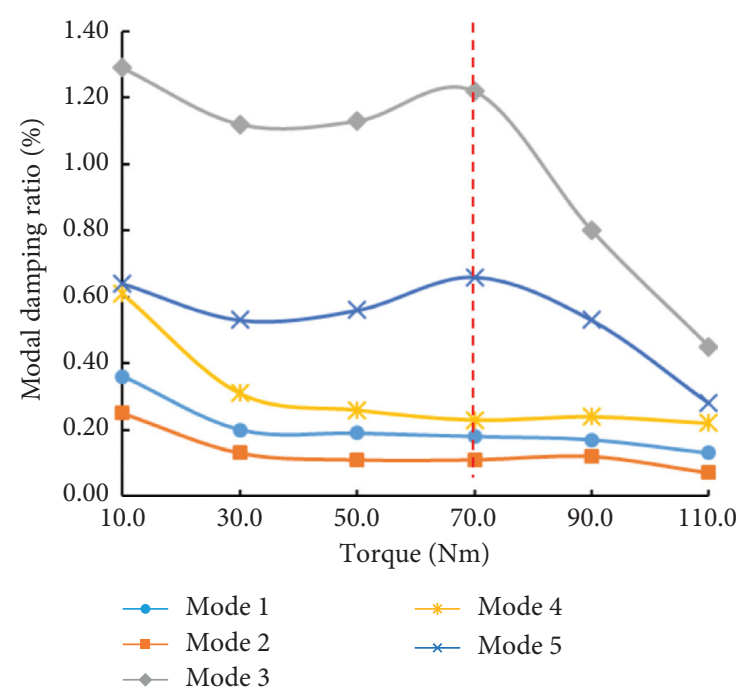

Figure 8: Modal damping versus preload from 10 to $110 \mathrm{Nm}$.

considered using the strain energy method. Therefore, the variation of natural frequency versus preload is due to the stiffness of the zero-length contact element. To demonstrate the influence of contact stiffness on the natural frequency clearly, we carry out a series of undamped modal analysis.

First of all, we develop an appropriate objective function, i.e., the 2-norm of a relative error residual:

$$
f_{\text {obj }}=\left\|\frac{\boldsymbol{\omega}_{m}-\boldsymbol{\omega}_{s}\left(\bar{k}_{c}\right)}{\boldsymbol{\omega}_{m}}\right\|_{2},
$$

where $\boldsymbol{\omega} \in \mathbb{R}^{5 \times 1}$ includes five bending eigenfrequencies, subindexes $m$ and $s$ denote measured and simulated results, respectively, and $\bar{k}_{c}$ represents dimensionless bending stiffness of the contact element that is the ratio of the revolute stiffness of the contact element concerning that of the adjacent beam element.

The optimization problem can be expressed as

$$
\left\{\begin{array}{l}
\min f_{\text {obj }}\left(\bar{k}_{c}\right), \\
\text { subject to } \bar{k}_{c} \in\left[\bar{k}_{c}^{l b} \bar{k}_{c}^{u b}\right],
\end{array}\right.
$$

where $\bar{k}_{c}^{l b}$ and $\bar{k}_{c}^{u b}$ denote the lower bound and upper bound of the variable.

To find the optimized stiffness parameters, Particle Swarm Optimization is adopted to solve the problem. The global minimal objective is achieved by using the PSO algorithm. The optimized stiffness parameters and the corresponding residual errors are collected in Figure 9. The contact stiffness demonstrates a bilinear behavior that is due to the interference fit of the contact pairs. A similar result has been reported in [31]. The $2^{\text {nd }}$ norm of the deviations of the relative error for the five eigenfrequencies is below $4.0 \%$.

3.3. Sensitivity Analysis. Sensitivity analysis is a common method to choose the most influential inputs for model updating. In this work, we have only one input parameter, contact stiffness $k_{c}$, for model updating. Therefore, sensitivity analysis of the eigenvalues with respect to the contact stiffness can be used to better understand the trend of the natural frequency with respect to preloads, as depicted in Figure 7.

Concerning the undamped system

$$
\left(\mathbf{K}\left(k_{c}\right)-\lambda_{i} \mathbf{M}\right), \quad \vartheta_{i}=0, i=1, \ldots, 5,
$$

the derivative of the eigenvalue $\lambda_{i}$ with respect to the contact stiffness $k_{c}$ can be expressed as follows [39]:

$$
\frac{\partial \lambda_{i}}{\partial k_{c}}=\vartheta_{i}^{T}[\frac{\partial \mathbf{K}}{\partial k_{c}}-\lambda_{i} \underbrace{\frac{\partial \mathbf{M}}{\partial k_{c}}}_{=0}] \vartheta_{i}=\vartheta_{i}^{T} \frac{\partial \mathbf{K}}{\partial k_{c}} \vartheta_{i} .
$$

The derivative of the stiffness matrix $\mathbf{K}$ with respect to the contact stiffness $k_{c}$ reads

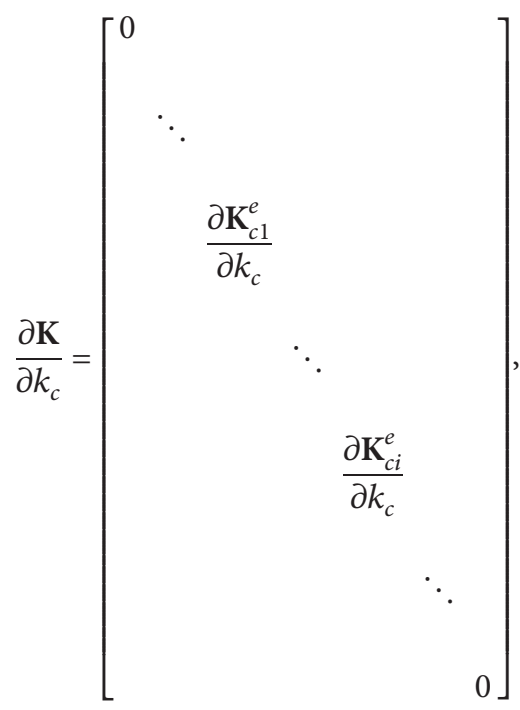




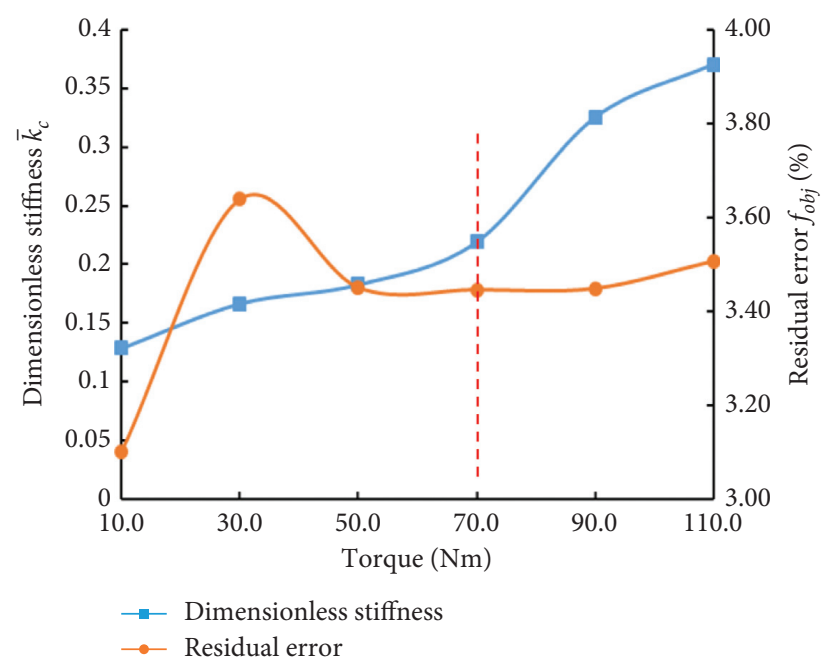

FIGURE 9: Optimized dimensionless stiffness and the residual error using the PSO algorithm.

where $\left(\partial \mathbf{K}_{c i}^{e} / \partial k_{c}\right)$ denotes the derivative of the stiffness matrix of the $i$ th contact element, which can be calculated as

$$
\frac{\partial \mathbf{K}_{c i}^{e}}{\partial k_{c}}=\left[\begin{array}{cccccccc}
0 & 0 & 0 & 0 & 0 & 0 & 0 & 0 \\
0 & 1 & 0 & 0 & 0 & -1 & 0 & 0 \\
0 & 0 & 0 & 0 & 0 & 0 & 0 & 0 \\
0 & 0 & 0 & 1 & 0 & 0 & 0 & -1 \\
0 & 0 & 0 & 0 & 0 & 0 & 0 & 0 \\
0 & -1 & 0 & 0 & 0 & 1 & 0 & 0 \\
0 & 0 & 0 & 0 & 0 & 0 & 0 & 0 \\
0 & 0 & 0 & -1 & 0 & 0 & 0 & 1
\end{array}\right] .
$$

Substituting equations (13) and (12) into equation (11) yields

$$
\frac{\partial \lambda_{i}}{\partial k_{c}}=\sum_{i=1}^{n_{c}} \vartheta_{c i}^{T} \frac{\partial \mathbf{K}_{c i}^{e}}{\partial k_{c}} \vartheta_{c i},
$$

where $n_{c}$ denotes the number of contact elements.

Due to the symmetry of the rotor system, we only consider the variables in the $y$-axis, and equation (14) can be simplified as

$$
\frac{\partial \lambda_{i}}{\partial k_{c}}=\sum_{i=1}^{n_{c}}\left(\bar{\phi}_{y, n_{i}+1}^{e}-\bar{\phi}_{y, n_{i}}^{e}\right)^{2} .
$$

Therefore, the eigenvalue with respect to the lumped contact stiffness can be calculated by the normalized rotating angle of the contact elements $\bar{\phi}_{y, n_{i}+1}^{e}$ and $\bar{\phi}_{y, n_{i}}^{e}$.

The normalized displacement $\bar{y}$ and normalized rotational angle $\bar{\Phi}$ for the five bending modes are plotted in Figure 10. There exist abrupt changes of the rotational angle at four contact nodes 20,24, 28, and 32. Hence, the sensitivity can be calculated by using the corresponding angle at four contact pairs. For a clear description, we introduce the dimensionless sensitivity:

$$
\bar{s}=\frac{\partial \lambda_{i}}{\partial k_{c}} \cdot \frac{k_{c 0}}{\lambda_{0}}
$$

where $k_{c 0}$ and $\lambda_{0}$ represent the stiffness of the adjacent beam element and the first eigenvalue, respectively. The results are displayed in Figure 11. The $3^{\text {rd }}$ and $5^{\text {th }}$ eigenvalue are most influenced by the input variable $k_{c}$, validating the modal tests depicted in Figure 7.

\section{Global Eigenvalue Analysis}

To study the influence of the contact element on modal parameters, we further perform a global eigenvalue analysis. Firstly, we introduce two dimensionless parameters to denote the stiffness and damping of the contact element:

$$
\begin{aligned}
& \bar{k}_{c}=\frac{k_{c}}{k_{0}}, \\
& \bar{d}_{c}=\frac{\mathrm{d}_{c} \omega_{0}}{k_{0}},
\end{aligned}
$$

where $k_{0}$ denotes the reference stiffness and $\omega_{0}$ is the reference frequency. According to different preloads on the tie bolt, we have six optimized stiffness coefficients, as depicted in Figure 9.

Figure 12 depicts a global eigenvalue for five bending modes with different preloads. Along the arrow in each plot, we apply an increasing stiffness that is obtained from model updating, as shown in Figure 9. We observe a smaller circle with a growing stiffness. Thus, the overall damping of all modes is reduced by increasing the pretension, which is also witnessed in Figure 8. For a specific contact stiffness, if we increase the dimensionless damping $\bar{d}_{c}$ from zero to infinity, the curve goes upwards in the clockwise direction. Increasing damping tends to stiffen the rotor since the 

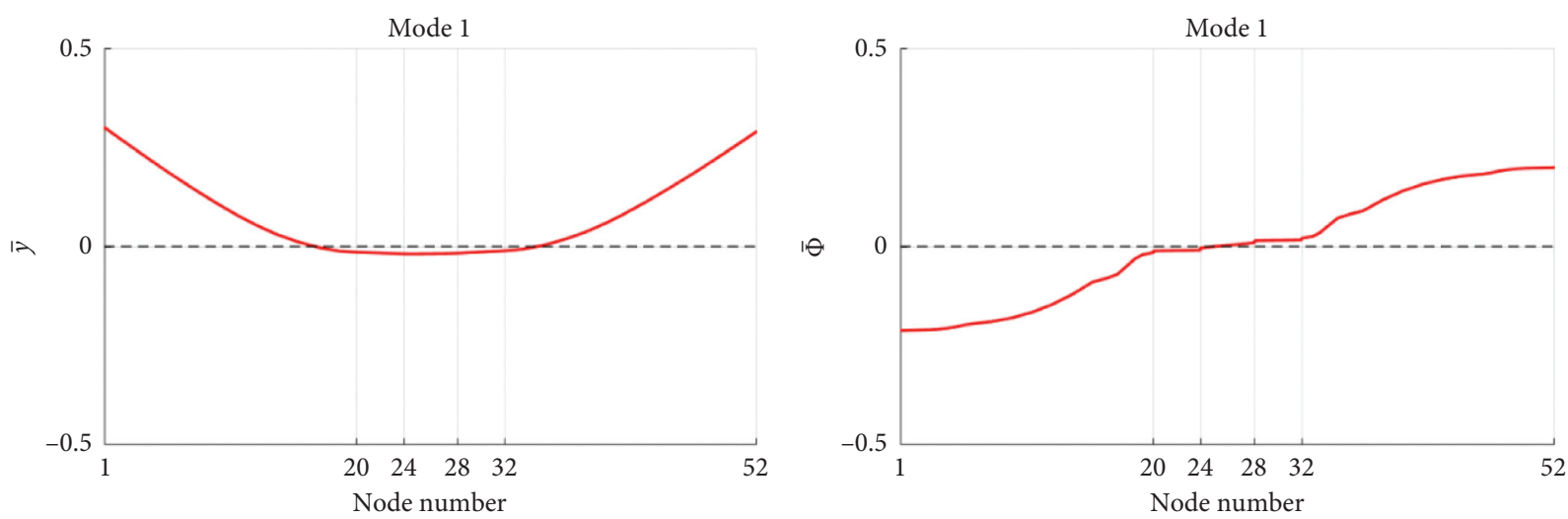

(a)
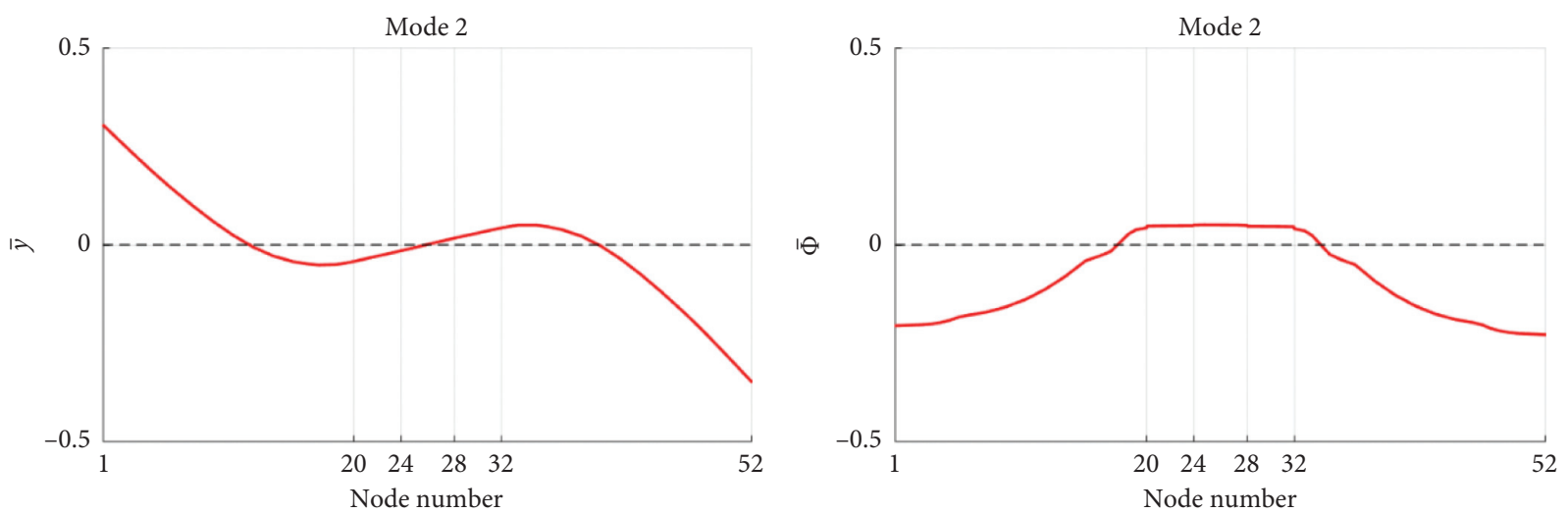

(b)
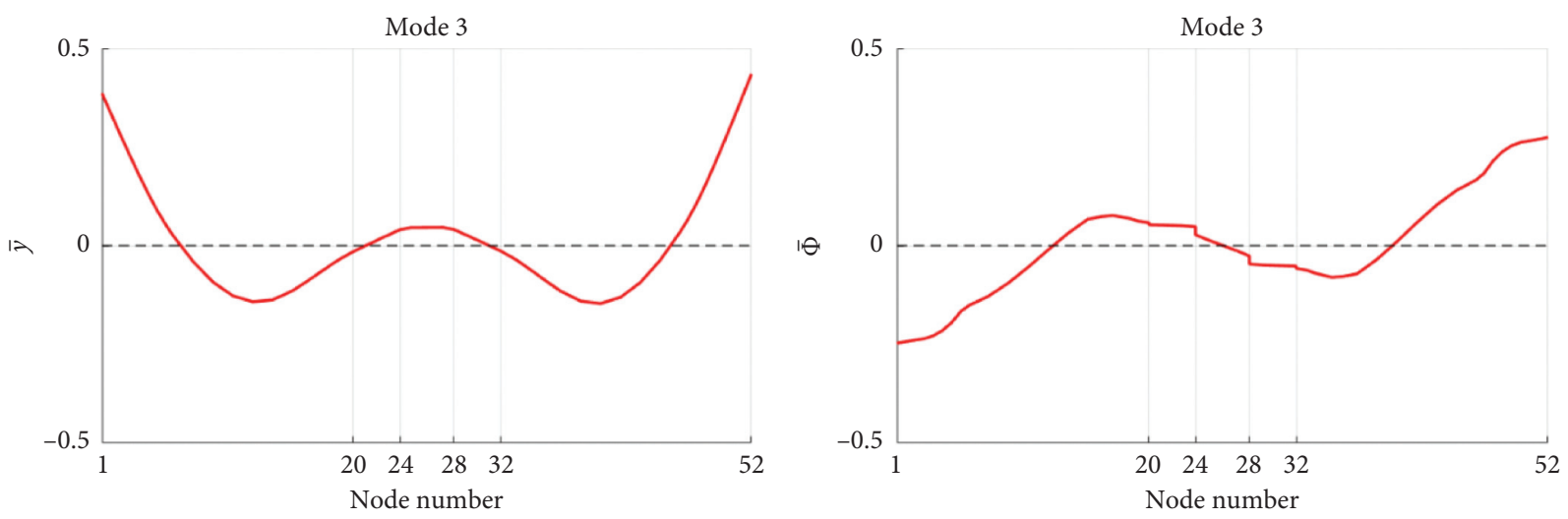

(c)
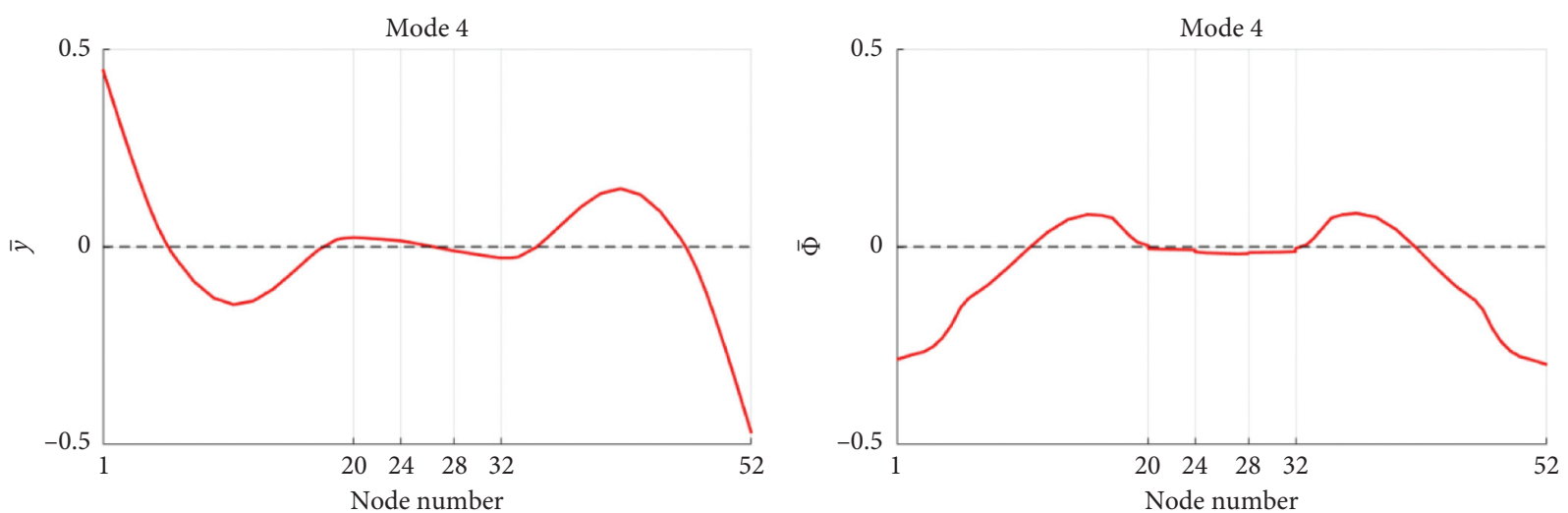

(d)

Figure 10: Continued. 

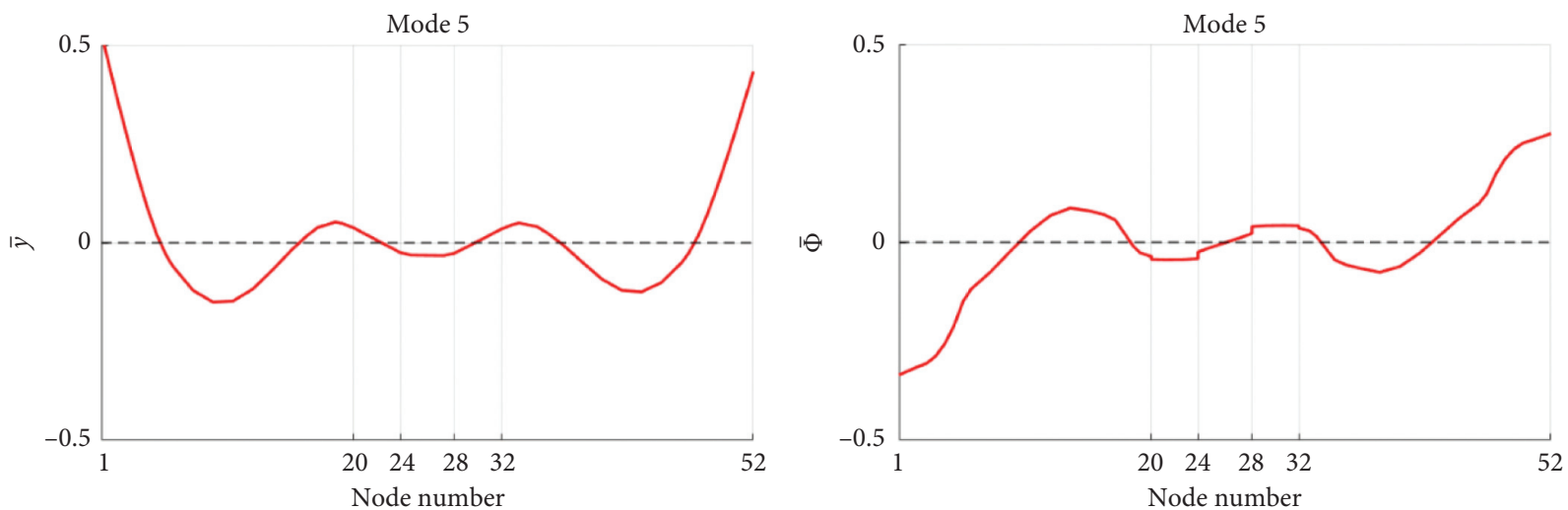

(e)

Figure 10: Normalized mode shape of the tie-bolt rotor: displacement $\bar{y}$ and rotational angle $\bar{\Phi}$.

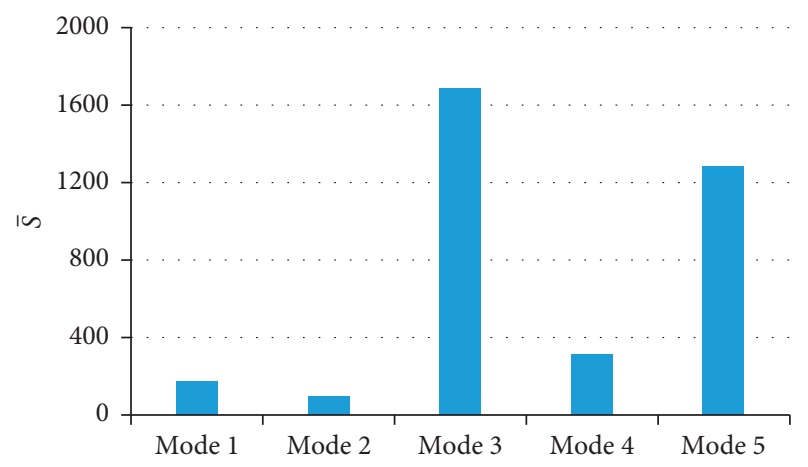

FIgURE 11: Dimensionless sensitivity of 5 modes with respect to the contact stiffness.

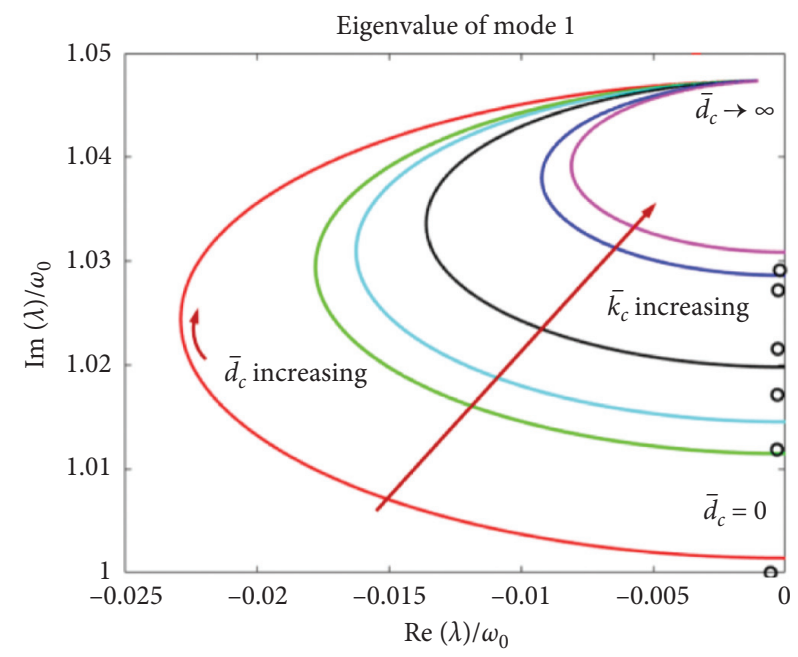

(a)

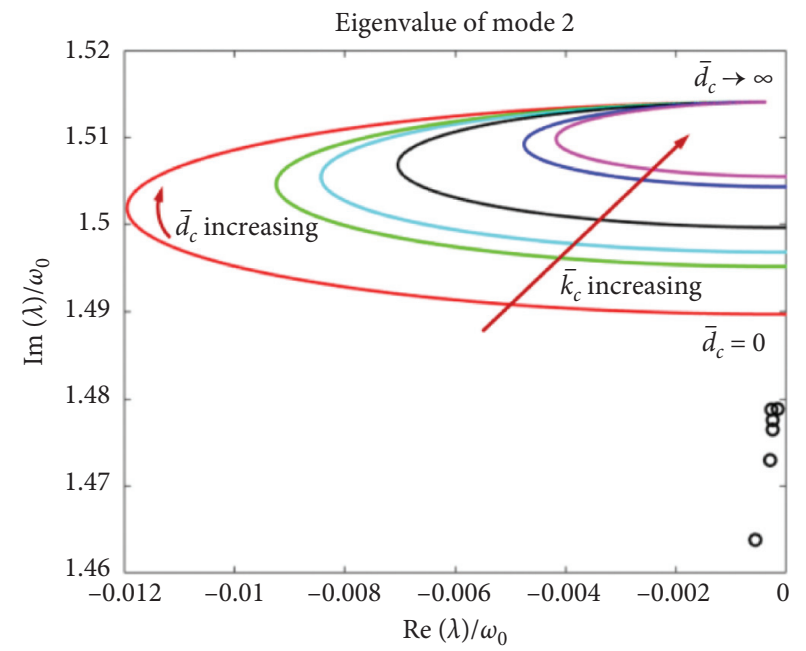

(b)

Figure 12: Continued. 


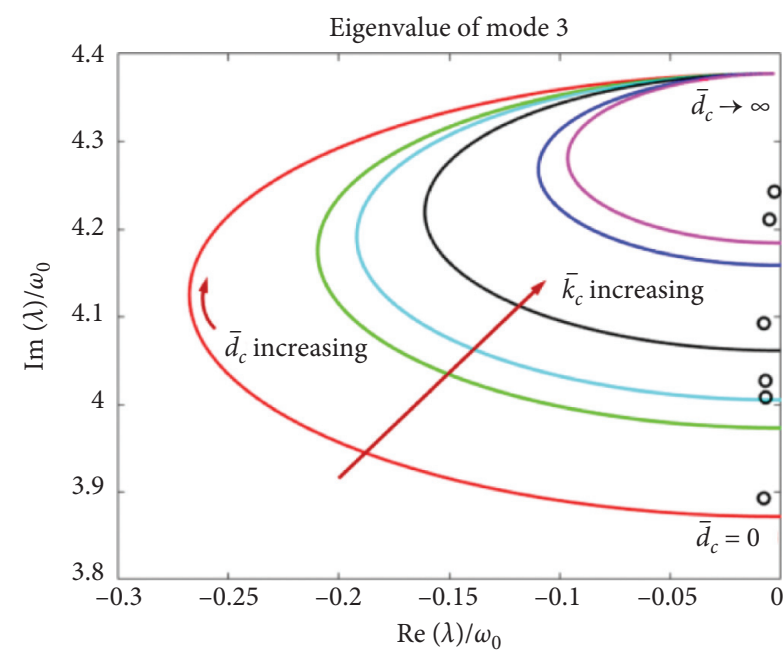

(c)

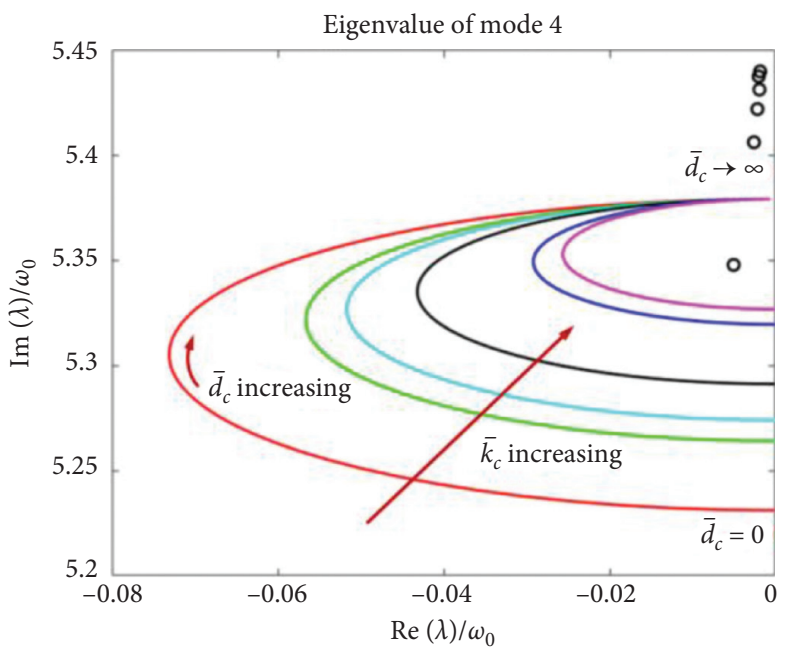

(d)

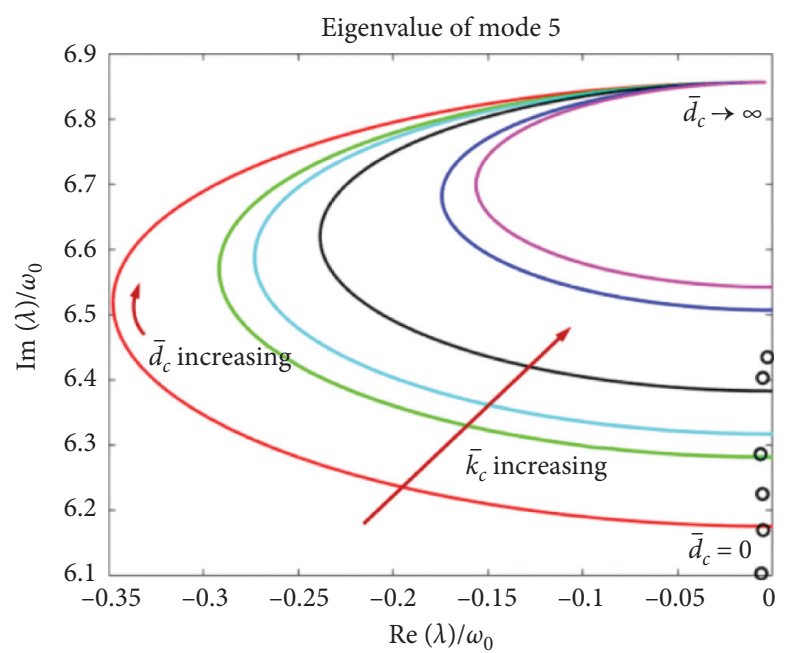

(e)

FIGURE 12: Root locus for varying joint stiffness (along the direction of the arrow, the dimensionless stiffness $\bar{k}_{c}=0.13,0.17,0.18,0.21,0.33$, and 0.37 ; the black circle denotes experimental results).

imaginary part of the eigenvalue is growing. More importantly, the modal damping is increasing by increasing the revolute damping but there is a turning point. Beyond that, increasing the value yields reduced modal damping. That means, the contact element participates less concerning the modal vibration and, therefore, introduces less damping to the system.

For a clear comparison, we summarize the global eigenvalue of five modes in Figure 13. For symmetric modes, i.e., modes 1,3 , and 5 , the maximal modal damping increases gradually. However, the corresponding damping of the contact element decreases from 0.1365 to 0.0333 . In contrast, for antisymmetric modes 2 and 4, the influence of damping of the contact element is relatively small. The results show that symmetric modes entail more participation of the contact element in the modal analysis compared to antisymmetric modes.

\section{Discussion}

To consider the influence of contact interfaces on the overall dynamics of connected structures, zero-length elements and thin-layer elements have been widely applied. In a previous paper [40], the contact stiffness and damping have been adjusted using the thin-layer element for the tiebolt rotor. The modulus of elasticity is optimized to minimize the error between simulated and measured frequencies. To consider the influence of the damping properties, two proportional parameters with respect to the stiffness matrix are introduced. The advantage of the thinlayer element method is a convenient parameter configuration for the finite element model. In particular, for the connected structure with multiple contact interfaces, the thin-layer element entails cost-efficient modeling. However, we have encountered two problems: (i) the mesh size 


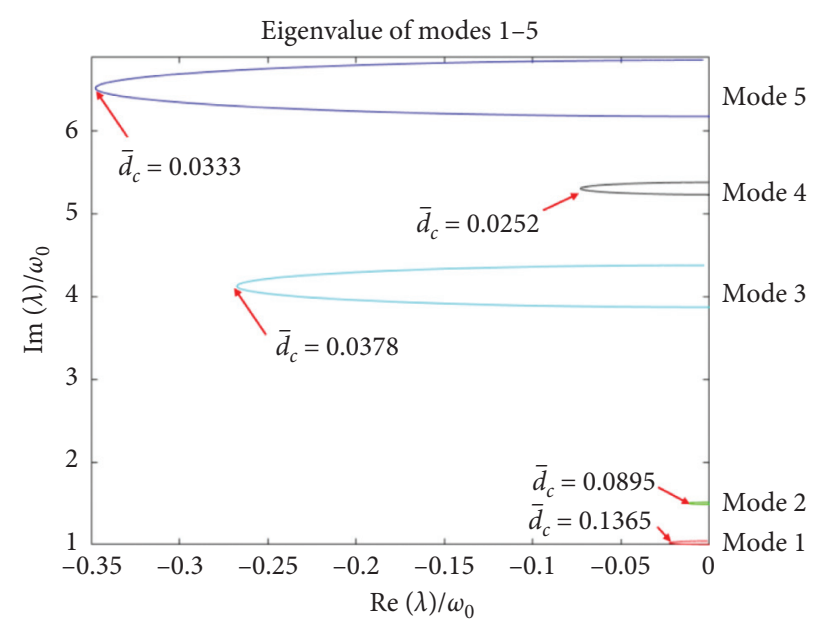

FIGURE 13: Root locus for varying joint damping $\left(\bar{k}_{c}=0.13\right)$.

of the thin-layer element should be much smaller to meet the meshing requirement for the $3 \mathrm{D}$ model, which might need a large amount of computational time for model updating; (ii) for commercial simulation tools, the simplified damping model may be inaccurate. For instance, Rayleigh damping cannot describe the damping properties caused by contact very well.

Due to the two practical difficulties as discussed in the previous contribution, we develop the rotor model using the beam element and the lumped spring-damper element. Compared to the thin-layer element, some advantages can be achieved as follows:

(i) The computational cost is greatly reduced which makes it possible for global eigenvalue evaluation.

(ii) Analytical sensitivity evaluation of the contact element concerning the eigenvalue can be obtained because the coupling relationship is explicitly expressed.

(iii) Nonlinear properties can be easily incorporated using the lumped spring-damper elements. For unbalance response or transient simulation, the zero-length contact element can be used more advantageously.

It should be stressed that the results of the current paper cannot be applied to arbitrary connected structures. The main restrictions are as follows:

(i) Static properties using experimental modal testing have been studied. The nonlinear phenomenon due to macroslip and the excitation amplitude is not discussed.

(ii) Unbalance excitation and centrifugal effects have a great influence on the contact status that is not taken into account.

(iii) The influence of interference fits has been demonstrated in the current paper. However, a further detailed study should be implemented for validation.

\section{Conclusions}

In this paper, the influence of contact stiffness and damping on modal responses of a tie-bolt rotor has been investigated. Model updating is carried out to obtain the optimized stiffness of the contact element using the PSO algorithm. It reveals that the interference fit entails two different contact statuses that are distinguished by the turning point at the preload of $70 \mathrm{Nm}$.

The sensitivity of the eigenvalue with respect to contact stiffness is relevant to the rotational angle of contact elements. From the dimensionless sensitivity plot, we observe that the $3^{\text {rd }}$ and $5^{\text {th }}$ modes are more sensitive to preload. A global eigenvalue analysis demonstrates the influence of the linear stiffness and damping of the contact element on the modal parameters. A larger stiffness of the contact element tends to reduce the modal damping that agrees well with the experimental results. For a specific contact stiffness, there is a turning point concerning the damping coefficient of the contact element that yields maximal modal damping.

\section{Nomenclature}

$\mathbf{B}_{0}$ and $\mathbf{B}_{c}$ : Damping matrix of beam element and contact element

$D_{e}^{i}: \quad \quad$ Equivalent stiffness diameter of rotor element $i$

$d_{c}$ and $\bar{d}_{c}$ : Damping of the contact element and

E: $\quad$ Elasticity modulus

$f_{\text {obj: }} \quad$ Objective function for optimization

G: $\quad$ Gyroscopic matrix

I: $\quad$ Inertial moment of the rotor

$\mathbf{K}_{0}$ and $\mathbf{K}_{\mathrm{c}}$ : Stiffness matrix of the beam element and the contact element

$k_{c}$ and $\bar{k}_{c}$ : Stiffness of the contact element and dimensionless stiffness of the contact element

$k_{a}: \quad \quad \quad \quad$ Axial stiffness of contact element

$k_{0}$ : $\quad$ Reference stiffness (the stiffness of underlying beam element)

$l^{e}: \quad \quad$ Length of the rotor element 
M:

Mass matrix

M:

$\mathbf{r}^{e}$ :

$\bar{s}:$

$U_{b}$ :

Bending moment

Coordinate of the rotor element

Dimensionless sensitivity

Strain energy of the rotor under bending moment

$y_{n}^{e}$ and $y_{n+1}^{e}$ : Translational displacement at node $n$ and $n+1$ of rotor element in the $y$-axis

$\bar{y}: \quad \quad \quad$ Normalized translational displacement in the $y$-axis

z: $\quad$ State vector involving displacement and velocity vector

$\lambda_{i}$ : $\quad$ Eigenvalue of the $i^{\text {th }}$ mode

$\phi_{n}^{e}$ and $\phi_{n+1}^{e}$ : Rotational displacement at node $n$ and $n+1$ of the rotor element

$\bar{\phi}$ : $\quad$ Normalized rotational displacement of the rotor

$\vartheta_{\mathrm{ci}}: \quad \quad \quad \quad$ Normalized mode shape of $i^{\text {th }}$ mode

$\omega_{m}$ and $\omega_{s}: \quad$ Measured and simulated eigenfrequencies

$\Omega: \quad$ Rotational speed of the rotor.

\section{Appendix}

\section{Element Matrices for the Rotor Model}

$\left(\mathbf{M}_{T}+\mathbf{M}_{r}\right) \ddot{\mathbf{r}}(t)+\left(\mathbf{B}_{0}+\mathbf{B}_{c}+\mathbf{G}\right) \dot{\mathbf{r}}(t)+\left(\mathbf{K}_{r}+\mathbf{K}_{c}\right) \mathbf{r}(t)=\mathbf{F}$.

(1) Translational mass matrix $\mathbf{M}_{T}^{e}$ :

$$
\mathbf{M}_{T}^{e}=\frac{\rho A l}{420}\left[\begin{array}{cccccccc}
156 & 22 l & 0 & 0 & 54 & -13 l & 0 & 0 \\
22 l & 4 l^{2} & 0 & 0 & 13 l & -3 l^{2} & 0 & 0 \\
0 & 0 & 156 & -22 l & 0 & 0 & 54 & 13 l \\
0 & 0 & -22 l & 4 l^{2} & 0 & 0 & -13 l & -3 l^{2} \\
54 & 13 l & 0 & 0 & 156 & -22 l & 0 & 0 \\
-13 l & -3 l^{2} & 0 & 0 & -22 l & 4 l^{2} & 0 & 0 \\
0 & 0 & 54 & -13 l & 0 & 0 & 156 & 22 l \\
0 & 0 & 13 l & -3 l^{2} & 0 & 0 & 22 l & 4 l^{2}
\end{array}\right] .
$$

(2) Rotational mass matrix $\mathbf{M}_{R}^{e}$ :

$$
\mathbf{M}_{R}^{e}=\frac{\rho I}{30 l}\left[\begin{array}{cccccccc}
36 & 3 l & 0 & 0 & -36 & 3 l & 0 & 0 \\
3 l & 4 l^{2} & 0 & 0 & -3 l & -l^{2} & 0 & 0 \\
0 & 0 & 36 & -3 l & 0 & 0 & -36 & -3 l \\
0 & 0 & -3 l & 4 l^{2} & 0 & 0 & 3 l & -l^{2} \\
-36 & -3 l & 0 & 0 & 36 & -3 l & 0 & 0 \\
3 l & -l^{2} & 0 & 0 & -3 l & 4 l^{2} & 0 & 0 \\
0 & 0 & -36 & 3 l & 0 & 0 & 36 & 3 l \\
0 & 0 & -3 l & -l^{2} & 0 & 0 & 3 l & 4 l^{2}
\end{array}\right] .
$$

(3) Damping matrix of contact element $\mathbf{B}_{c}^{e}$ :

$$
\mathbf{B}_{c}^{e}=\left[\begin{array}{cccccccc}
0 & 0 & 0 & 0 & 0 & 0 & 0 & 0 \\
0 & \mathrm{~d} c & 0 & 0 & 0 & -\mathrm{d} c & 0 & 0 \\
0 & 0 & 0 & 0 & 0 & 0 & 0 & 0 \\
0 & 0 & 0 & \mathrm{~d} c & 0 & 0 & 0 & -\mathrm{d} c \\
0 & 0 & 0 & 0 & 0 & 0 & 0 & 0 \\
0 & -\mathrm{d} c & 0 & 0 & 0 & \mathrm{~d} c & 0 & 0 \\
0 & 0 & 0 & 0 & 0 & 0 & 0 & 0 \\
0 & 0 & 0 & -\mathrm{d} c & 0 & 0 & 0 & \mathrm{~d} c
\end{array}\right] .
$$

(4) Gyroscopic matrix $\mathbf{G}^{e}$ :

$$
\mathbf{G}^{e}=\frac{\rho I \Omega}{15 l}\left[\begin{array}{cccccccc}
0 & 0 & -36 & 3 l & 0 & 0 & 36 & 3 l \\
0 & 0 & -3 l & 4 l^{2} & 0 & 0 & 3 l & -l^{2} \\
36 & 3 l & 0 & 0 & 36 & -3 l & 0 & 0 \\
-3 l & -4 l^{2} & 0 & 0 & -3 l & -l^{2} & 0 & 0 \\
0 & 0 & -36 & 3 l & 0 & 0 & -36 & -3 l \\
0 & 0 & 3 l & l^{2} & 0 & 0 & 3 l & 4 l^{2} \\
-36 & -3 l & 0 & 0 & 36 & -3 l & 0 & 0 \\
-3 l & l^{2} & 0 & 0 & 3 l & -4 l^{2} & 0 & 0
\end{array}\right] .
$$


(5) Stiffness matrix of beam element $\mathbf{K}_{0}^{e}$ :

$$
\mathbf{K}_{0}^{e}=\frac{E I}{l^{3}}\left[\begin{array}{cccccccc}
12 & 6 l & 0 & 0 & -12 & 6 l & 0 & 0 \\
6 l & 4 l^{2} & 0 & 0 & -6 l & 2 l^{2} & 0 & 0 \\
0 & 0 & 12 & -6 l & 0 & 0 & -12 & -6 l \\
0 & 0 & -6 l & 4 l^{2} & 0 & 0 & 6 l & 2 l^{2} \\
-12 & -6 l & 0 & 0 & 12 & -6 l & 0 & 0 \\
6 l & 2 l^{2} & 0 & 0 & -6 l & 4 l^{2} & 0 & 0 \\
0 & 0 & -12 & 6 l & 0 & 0 & 12 & 6 l \\
0 & 0 & -6 l & 2 l^{2} & 0 & 0 & 6 l & 4 l^{2}
\end{array}\right] .
$$

(6) Stiffness matrix of contact element $\mathbf{K}_{c}^{e}$ :

$$
\mathbf{K}_{c}^{e}=\left[\begin{array}{cccccccc}
k a & 0 & 0 & 0 & -k a & 0 & 0 & 0 \\
0 & k c & 0 & 0 & 0 & -k c & 0 & 0 \\
0 & 0 & k a & 0 & 0 & 0 & -k a & 0 \\
0 & 0 & 0 & k c & 0 & 0 & 0 & -k c \\
-k a & 0 & 0 & 0 & k a & 0 & 0 & 0 \\
0 & -k c & 0 & 0 & 0 & k c & 0 & 0 \\
0 & 0 & -k a & 0 & 0 & 0 & k a & 0 \\
0 & 0 & 0 & -k c & 0 & 0 & 0 & k c
\end{array}\right] .
$$

\section{Data Availability}

The data used to support the findings of this study are available from the corresponding author upon request.

\section{Conflicts of Interest}

The authors declare that they have no conflicts of interest.

\section{Acknowledgments}

This work was supported by the National Nature Science Foundation of China (nos. 11902237 and 11872289) and Fundamental Research Funds for the Central Universities (XY22177).

\section{References}

[1] J. Hong, X. Chen, Y. Wang, and Y. Ma, "Optimization of dynamics of non-continuous rotor based on model of rotor stiffness," Mechanical Systems and Signal Processing, vol. 131, pp. 166-182, 2019.

[2] J. Gao, Q. Yuan, P. Li, Z. Feng, H. Zhang, and Z. Lv, "Effects of bending moments and pretightening forces on the flexural stiffness of contact interfaces in rod-fastened rotors," Journal of Engineering for Gas Turbines and Power, vol. 134, no. 10, Article ID 102503, 2012.

[3] S. Liu, Y. Ma, D. Zhang, and J. Hong, "Studies on dynamic characteristics of the joint in the aero-engine rotor system," Mechanical Systems and Signal Processing, vol. 29, pp. 120136, 2012.

[4] G. Mogenier, T. Baranger, R. Dufour, F. Besso, and L. Durantay, "Nonlinear centrifugal effects on a prestressed laminated rotor," Mechanism and Machine Theory, vol. 46, no. 10, pp. 1466-1491, 2011.

[5] Y.-C. Kim and K.-W. Kim, "Influence of lamination pressure upon the stiffness of laminated rotor," JSME International Journal Series C, vol. 49, no. 2, pp. 426-431, 2006.

[6] S. D. Garvey, J. E. T. Penny, M. I. Friswell, A. W. Lees, and E. Imech, "The stiffening effect of laminated rotor cores on flexible-rotor electrical machines," Vibrations in Rotating Machinery, vol. 2004, p. 202, 2004.

[7] P. Li, Q. Yuan, B. Zhao, and J. Gao, "Dynamics of a rodfastened rotor considering the bolt loosening effect," in Proceedings of the Turbomachinery Technical Conference and Exposition, Phoenix, Arizona, USA, June 2019.

[8] Z. Qin, Q. Han, and F. Chu, "Bolt loosening at rotating joint interface and its influence on rotor dynamics," Engineering Failure Analysis, vol. 59, pp. 456-466, 2016.

[9] Z. Qin and F. Chu, "Numerical studies on time-varying stiffness of disk-drum type rotor with bolt loosening," Journal of Physics: Conference Series, vol. 628, no. 1, Article ID 012076, 2015.

[10] W. K. Belvin, "Modeling of Joints for the Dynamic Analysis of Truss Structures," National Aeronautics and Space Administration, 1987.

[11] L. Wang, A. Wang, M. Jin, Q. Huang, and Y. Yin, "Nonlinear effects of induced unbalance in the rod fastening rotorbearing system considering nonlinear contact," Archive of Applied Mechanics, vol. 90, no. 5, pp. 917-943, 2020.

[12] Q. Yuan, J. Gao, and P. Li, "Nonlinear dynamics of the rodfastened jeffcott rotor," Journal of Vibration and Acoustics, vol. 136, no. 2, Article ID 021011, 2014.

[13] Z. Qin, Q. Han, and F. Chu, "Analytical model of bolted diskdrum joints and its application to dynamic analysis of jointed rotor," Proceedings of the Institution of Mechanical Engineers, Part C: Journal of Mechanical Engineering Science, vol. 228, no. 4, pp. 646-663, 2014.

[14] S. Bograd, P. Reuss, A. Schmidt, L. Gaul, and M. Mayer, "Modeling the dynamics of mechanical joints," Mechanical Systems and Signal Processing, vol. 25, no. 8, pp. 2801-2826, 2011.

[15] R. Lacayo, L. Pesaresi, J. Groß et al., "Nonlinear modeling of structures with bolted joints: a comparison of two approaches based on a time-domain and frequency-domain solver," Mechanical Systems and Signal Processing, vol. 114, pp. 413438, 2019.

[16] M. Bowden and J. Dugundji, "Joint damping and nonlinearity in dynamics of space structures," AIAA Journal, vol. 28, no. 4, pp. 740-749, 1990.

[17] L. Gaul, "Modeling of contact interfaces in built up structures by zero thickness elements," in Proceedings of the Conference \& Exposition on Structural Dynamics, Orlando, Florida, February 2008.

[18] Y. C. Zhang, Z. G. Du, L. M. Shi, and S. Q. Liu, "Determination of contact stiffness of rod-fastened rotors based on modal test and finite element analysis," Journal of Engineering for Gas Turbines and Power, vol. 132, no. 9, pp. 47-49, 2010. 
[19] C. S. Desai, M. M. Zaman, J. G. Lightner, and H. J. Siriwardane, "Thin-layer element for interfaces and joints," International Journal for Numerical and Analytical Methods in Geomechanics, vol. 8, no. 1, pp. 19-43, 1984.

[20] M. H. Mayer and L. Gaul, "Segment-to-segment contact elements for modelling joint interfaces in finite element analysis," Mechanical Systems and Signal Processing, vol. 21, no. 2, pp. 724-734, 2007.

[21] X. Yao, J. Wang, and X. Zhai, "Research and application of improved thin-layer element method of aero-engine bolted joints," Proceedings of the Institution of Mechanical Engineers, Part G: Journal of Aerospace Engineering, vol. 231, no. 5, pp. 823-839, 2017.

[22] F. Adel, S. Shokrollahi, M. Jamal-Omidi, and H. Ahmadian, "A model updating method for hybrid composite/aluminum bolted joints using modal test data," Journal of Sound and Vibration, vol. 396, pp. 172-185, 2017.

[23] L. Gaul and A. Schmidt, "Finite element simulation and experiments on rotor damping assembled by disc shrink fits," Mechanical Systems and Signal Processing, vol. 127, pp. 412422, 2019.

[24] L. Gaul and M. Mayer, "Efficient modelling of contact interfaces of joints in built up structures," in Proceedings of the 8th International Conference on Computer Methods and Experimental Measurements for Surface and Contact Mechanics, Las Vegas, Nevada, September 2007.

[25] S. M. Sah, J. J. Thomsen, M. Brøns, A. Fidlin, and D. Tcherniak, "Estimating bolt tightness using transverse natural frequencies," Journal of Sound and Vibration, vol. 431, pp. 137-149, 2018.

[26] M. Zhuo, L. H. Yang, and L. Yu, "Contact stiffness calculation and effects on rotordynamic of rod fastened rotor," in Proceedings of the ASME International Mechanical Engineering Congress and Exposition (IMECE), Phoenix, AZ, USA, November 2016.

[27] P. He, Z. S. Liu, and G. L. Wang, "Rotor dynamic analysis of tie-bolt fastened rotor based on elastic-plastic contact," in Proceedings of ASME Turbo Expo 2011, pp. 365-373, Vancouver, Canada, 2011.

[28] L. Gaul and J. Lenz, "Nonlinear dynamics of structures assembled by bolted joints," Acta Mechanica, vol. 125, no. 1-4, pp. 169-181, 1997.

[29] D. J. Segalman, "A four-parameter Iwan model for lap-type joints," Journal of Applied Mechanics, vol. 72, no. 5, pp. 752-760, 2005.

[30] G. Zhao, Z. Xiong, X. Jin, L. Hou, and W. Gao, "Prediction of contact stiffness in bolted interface with natural frequency experiment and FE analysis," Tribology International, vol. 127, pp. 157-164, 2018.

[31] A. Rimpel and M. Leopard, "Simple contact stiffness model validation for tie bolt rotor design with butt joints and pilot fits," Journal of Engineering for Gas Turbines and Power, vol. 142, no. 1, Article ID 011014, 2019.

[32] F. R. Nizametdinov, Y. S. Romashin, A. L. Berne, and M. K. Leontyev, "Investigation of bending stiffness of gas turbine engine rotor flanged connection," Journal of $\mathrm{Me}$ chanics, vol. 36, pp. 1-8, 2020.

[33] S. Daouk, F. Louf, C. Cluzel, O. Dorival, L. Champaney, and S. Audebert, "Study of the dynamic behavior of a bolted joint under heavy loadings," Journal of Sound and Vibration, vol. 392, pp. 307-324, 2017.

[34] F. Huda, I. Kajiwara, N. Hosoya, and S. Kawamura, "Bolt loosening analysis and diagnosis by non-contact laser excitation vibration tests," Mechanical Systems and Signal Processing, vol. 40, no. 2, pp. 589-604, 2013.

[35] Z. Zheng, Y. Xie, and D. Zhang, "Reduced-order modeling for stability and steady-state response analysis of asymmetric rotor using three-dimensional finite element model," Journal of Engineering for Gas Turbines and Power, vol. 141, no. 10, Article ID 101001, 2019.

[36] B. Schweizer, "Total instability of turbocharger rotors-Physical explanation of the dynamic failure of rotors with fullfloating ring bearings," Journal of Sound and Vibration, vol. 328, no. 1-2, pp. 156-190, 2009.

[37] H. D. Nelson, "A finite rotating shaft element using timoshenko beam theory," Journal of Mechanical Design, vol. 102, no. 4, pp. 793-803, 1980.

[38] M. I. Friswell, Dynamics of Rotating Machines (Cambridge Aerospace Series), Cambridge University Press, Cambridge, UK, 2010.

[39] R. L. Fox and M. P. Kapoor, "Rates of change of eigenvalues and eigenvectors," AIAA Journal, vol. 6, no. 12, pp. 2426-2429, 1968.

[40] P. Li and Q. Yuan, "Determination of contact stiffness and damping of a tie-bolt rotor with interference fits using model updating with thin-layer elements," Shock and Vibration, vol. 2020, Article ID 8872401, 10 pages, 2020. 